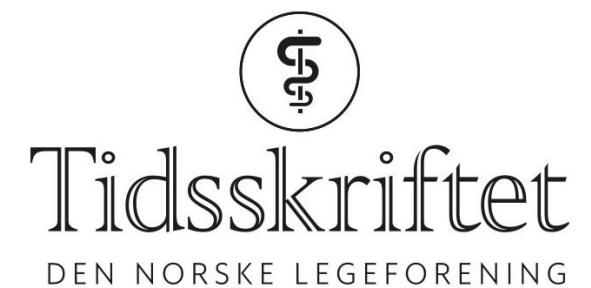

\title{
Intensivering av antitrombotisk behandling ved kronisk aterosklerotisk sykdom
}

DEBATT

MARITA KNUDSEN POPE

E-post: marita.knudsen.pope@gmail.com

Marita Knudsen Pope er lege i spesialisering ved Hamar sykehus.

Forfatteren har fylt ut ICMJE-skjemaet og oppgir ingen interessekonflikter.

\section{WALEED GHANIMA}

Waleed Ghanima er overlege ved Indremedisinsk klinikk, Sykehuset Østfold, forskningssjef ved Sykehuset Østfold og professor ved Avdeling for blodsykdommer, Universitetet i Oslo. Forfatteren har fylt ut ICMJE-skjemaet og oppgir ingen interessekonflikter.

\section{DAN ATAR}

Dan Atar er professor og overlege i kardiologi ved Oslo universitetssykehus og forskningsleder for Medisinsk klinikk, Oslo universitetssykehus og Universitetet i Oslo.

Forfatteren har fylt ut ICMJE-skjemaet og oppgir ingen interessekonflikter.

Intensivering av antitrombotisk behandling kan redusere morbiditet og mortalitet hos pasienter med etablert aterosklerotisk sykdom. Behandlingsstrategien bør inkorporeres i norske retningslinjer.

Aterosklerose forårsaker svekkelse eller forsnevring av arterievegger og er patofysiologisk årsak til mange kardiovaskulære sykdommer. Erosjon eller ruptur av aterosklerotiske lesjoner, med koagulasjonsfaktor- og blodplateaktivering, kan gi videre fortetning med trombedannelse og perifer embolisering (1).

I 2016 brukte mer enn én av fem i Norge medikamenter for å behandle eller forebygge kardiovaskulær sykdom (2). Selv om insidensen av hjerte- og karsykdommer er i nedgang, forventes en $\emptyset$ kning i befolkningsandelen som lever med tilstandene. Dette er en følge av bedret overlevelse og en aldrende befolkning (3).

\section{Forhøyet kardiovaskulær risiko}

Etablerte, forebyggende tiltak mot kardiovaskulær sykdom er livsstilintervensjoner, antidiabetika, blodtrykksregulerende og kolesterolsenkende medikamenter samt eventuelt revaskulariseringsbehandling $(4,5)$. Sekundærprofylakse inkluderer antitrombotisk medikasjon ved koronar arteriesykdom, karotisstenose eller symptomatisk perifer arteriesykdom. 
Pasienter med etablert hjerte- og karsykdom er betydelig utsatt for alvorlige kardiovaskulære hendelser (kardiovaskulær død, myokardinfarkt og slag), selv ved effektiv behandling og god etterlevelse (1). Risikoen har blitt estimert til hele 20 \% etter 3-4 år $(1,6)$.

Hos pasienter med koronar arteriesykdom er perifer arteriesykdom en kjent risikomarkør for alvorlig utfall, og pasienter med slik sykdom har forhøyet risiko for alvorlige

kardiovaskulære hendelser (7). Pasienter med perifer arteriesykdom er også betydelig utsatt for alvorlige ekstremitetshendelser (akutt iskemi, amputasjon og kirurgisk revaskularisering)(5).

\section{Nye studier av antitrombotiske regimer}

Flere studier med ulike antitrombotiske regimer for pasienter med kardiovaskulær sykdom er publisert, men total nytte sett mot risiko har ofte vært ugunstig, blant annet grunnet $\emptyset \mathrm{kning}$ i intrakraniale og/eller fatale blødninger $(4,6)$. Dette var annerledes i to nylig publiserte studier.

PEGASUS-TIMI 54-studien (Prevention of Cardiovascular Events in Patients with Prior Heart Attack Using Ticagrelor Compared to Placebo on a Background of Aspirin-Thrombolysis In Myocardial Infarction) $(8,9)$ inkluderte 21162 pasienter med gjennomgått myokardinfarkt. Dobbel platehemming med $60 \mathrm{mg}$ tikagrelor to ganger daglig pluss acetylsalisylsyre $75 \mathrm{mg}$ daglig gav signifikant reduksjon av alvorlige kardiovaskulære hendelser $(\mathrm{HR} 0,84, \mathrm{p}=$ o,o04) sammenliknet med acetylsalisylsyre i monoterapi. I tikagrelorgruppen ble antallet store blødninger doblet, men det var ingen signifikant økning i fatale eller intrakraniale blødninger. Pasienter med perifer arteriesykdom fikk signifikant nedgang i mortalitet i

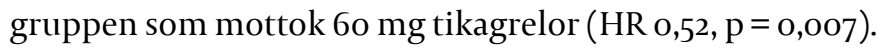

Intensivert antitrombotisk behandling gav betydelig reduksjon av systemiske, iskemiske komplikasjoner hos pasienter med kardiovaskulær sykdom

COMPASS-studien (Cardiovascular Outcomes for People Using Anticoagulation Strategies) $(10,11)$ inkluderte 27395 pasienter med stabil aterosklerotisk sykdom, koronar og/eller perifer. Acetylsalisylsyre pluss 2,5 mg rivaroksaban gav signifikant færre alvorlige kardiovaskulære hendelser (HR o,76, p < o,oo1) og signifikant reduksjon i mortalitet (HR $\mathrm{o}, 82, \mathrm{p}=\mathrm{o}, 01$ ) sammenliknet med acetylsalisylsyre i monoterapi. Store blødninger $\emptyset \mathrm{kte}$ signifikant (3,1\% vs. 1,9\%, p < o,oo1), men ikke intrakraniale eller fatale blødninger. Alvorlige ekstremitetshendelser ble halvert i subgruppen med perifer arteriesykdom $(\mathrm{HR} 0,54, \mathrm{p}=$ o,005). En uavhengig sikkerhetskomité avsluttet COMPASS-studien før planlagt tid grunnet tydelig intervensjonseffekt.

\section{Vurdering}

I de nevnte studiene gav intensivert antitrombotisk behandling betydelig reduksjon av systemiske, iskemiske komplikasjoner hos pasienter med kardiovaskulær sykdom, og sågar bedret overlevelse. Behandlingsregimene kan følgelig bedre prognosen til en spesielt risikoutsatt pasientpopulasjon. Gevinsten utmerket seg spesielt hos pasienter med perifer arteriesykdom. Intensivert antitrombotisk medikasjon øker alltid blødningsrisikoen og må inngå i nytte-risiko-vurderingen.

Statens legemiddelverk har med bakgrunn i studiene utvidet indikasjonene for behandling med legemidlene. Langtidsbehandlingene er kommet inn i blåreseptordningen.

Europeiske retningslinjer ved koronar arteriesykdom, publisert i januar 2020, sier at man ved høy/moderat risiko for iskemisk hendelse bør/kan vurdere å legge til et antitrombotisk legemiddel til acetylsalisylsyrebehandlingen (4).

I lys av det ovennevnte mener vi at studiefunnene bør inkorporeres i norske retningslinjer. Pasienter med etablert koronar eller symptomatisk perifer arteriesykdom og høy risiko for iskemisk hendelse, uten høy blødningsrisiko, bør vurderes for tilleggsbehandling med 
rivaroksaban eller tikagrelor (etter myokardinfarkt). Pasientene bør involveres i nytte-risiko-drøftingen og i avgjørelsen av behandlingsstrategi.

\section{LITTERATUR:}

1. Fox KAA, Metra M, Morais J et al. The myth of 'stable' coronary artery disease. Nat Rev Cardiol 2020; 17: 9-21. [PubMed][CrossRef]

2. Folkehelseinstituttet. Statistikk fra Reseptregisteret. http://www.reseptregisteret.no/Prevalens.aspx Lest 4.5.2020.

3. Folkehelserapporten. Hjerte- og karsykdommer i Norge. https://www.fhi.no/nettpub/hin/ikke-smittsomme/Hjerte-kar/ Lest 4.5.2020.

4. Knuuti J, Wijns W, Saraste A et al. 2019 ESC Guidelines for the diagnosis and management of chronic coronary syndromes. Eur Heart J 2020; 41: 407-77. [PubMed][CrossRef]

5. Aboyans V, Ricco JB, Bartelink MEL et al. 2017 ESC Guidelines on the diagnosis and treatment of peripheral arterial diseases. Eur Heart J 2018; 39: 763-816. [PubMed][CrossRef]

6. Fox KAA, Eikelboom JW, Anand SS et al. Anti-thrombotic options for secondary prevention in patients with chronic atherosclerotic vascular disease: what does COMPASS add? Eur Heart J 2019; 40: 1466-71. [PubMed][CrossRef]

7. Lewis BS, Atar D. Peripheral arterial disease and limb salvage: a new arena for the cardiologist. Eur Heart J Cardiovasc Pharmacother 2018; 4: 136-7. [PubMed][CrossRef]

8. Bonaca MP, Bhatt DL, Cohen M et al. Long-term use of ticagrelor in patients with prior myocardial infarction. N Engl J Med 2015; 372: 1791-80o. [PubMed][CrossRef]

9. Bonaca MP, Bhatt DL, Storey RF et al. Ticagrelor for prevention of ischemic events after myocardial infarction in patients with peripheral artery disease. J Am Coll Cardiol 2016; 67: 2719-28.

[PubMed][CrossRef]

10. Anand SS, Bosch J, Eikelboom JW et al. Rivaroxaban with or without aspirin in patients with stable peripheral or carotid artery disease: an international, randomised, double-blind, placebo-controlled trial. Lancet 2018; 391: 219-29. [PubMed][CrossRef]

11. Eikelboom JW, Connolly SJ, Bosch J et al. Rivaroxaban with or without aspirin in stable cardiovascular disease. N Engl J Med 2017;377: 1319-30. [PubMed][CrossRef]

Publisert: 24. juni 2020. Tidsskr Nor Legeforen. DOI: 10.4045/tidsskr.20.0066

Mottatt 24.1.2020, første revisjon innsendt 7.5.2020, godkjent 14.5.2020.

(C) Tidsskrift for Den norske legeforening 2020. Lastet ned fra tidsskriftet.no 